\title{
A Modelagem Matemática no contexto do estágio supervisionado segundo as compreensões de futuros professores
}

\section{Mathematical Modeling in supervised teaching practice in the understanding of future teachers}

\author{
Wellington Piveta Oliveira ${ }^{1}$ \\ https://orcid.org/0000-0002-3840-1972 \\ Lilian Akemi Kato ${ }^{2}$ \\ https://orcid.org/0000-0001-8770-3873
}

\begin{abstract}
Resumo: Neste artigo, tecemos algumas reflexões acerca das compreensões dos estagiários quanto à inserção da Modelagem Matemática no Estágio Supervisionado. A interrogação que nos move: O que os estagiários que vivenciaram a inserção da Modelagem no Estágio compreendem sobre essa experiência? conduziu-nos ao desenvolvimento deste estudo qualitativo segundo a postura fenomenológico-hermenêutica, modo pelo qual emergiram as reflexões sobre essa inserção, na perspectiva dos estagiários. Reunimos depoimentos de estagiários que vivenciaram a experiência com a Modelagem no Estágio em uma universidade estadual paranaense e destacamos deles unidades de sentido, que, em um movimento de convergência, deram abertura a dois núcleos, os quais nos permitiram lançar as reflexões aqui empreendidas. Esse movimento nos mostrou que os estagiários reconhecem benefícios da Modelagem no contexto do Estágio como alternativa metodológica, caracterizando-se como uma configuração relevante para a formação inicial do professor. No entanto, destacaram obstáculos para poderem realizar o Estágio com Modelagem.
\end{abstract}

Palavras-chave: Modelagem matemática. Estágio supervisionado. Formação de professores.

\begin{abstract}
In this article we present some reflections on the trainees' understanding of Mathematical Modeling in their supervised teaching practice. The research question (What do trainees who have had this experience understand about the insertion of Modeling in the supervised practice?) has caused us to carry out this qualitative study according to the phenomenological-hermeneutic approach, through which reflections have emerged from the viewpoint of the trainees on this insertion. We collected testimonials by trainees who lived the experience with Modeling in the supervised practice in a state university of Paraná, Brazil. In those testimonials we highlight units of meaning that - in a movement of convergence - created two clusters that enabled us to formulate the reflections presented here. This movement showed us that trainees recognize the benefits of Modeling in the context of the supervised practice as a methodological alternative, characterizing a relevant configuration to initial teacher education; however, they highlight obstacles for them to be able to carry out the supervised practice with Modeling.
\end{abstract}

Keywords: Mathematical modeling. Supervised teaching practice. Teachers education.

\footnotetext{
${ }^{1}$ Universidade Estadual de Maringá (UEM), Programa de Pós-Graduação em Educação para a Ciência e a Matemática, Maringá, PR, Brasil.

${ }^{2}$ UEM, Departamento de Matemática, Maringá, PR, Brasil. E-mail: lakato@uem.br
} 


\section{Uma abertura à investigação}

Os debates e pesquisas sobre a Modelagem Matemática ${ }^{3}$ têm sido recorrentes no contexto da Educação Matemática desde meados da década de 1970, no Brasil. Esses debates, atrelados à emergência de práticas e pesquisas que refletem, de algum modo, sobre a inserção e a presença da Modelagem como prática pedagógica e outros aspectos, como os epistemológicos da própria Modelagem, as teorias de ensino e aprendizagem, a própria formação de professores, como os agendados por A. M. P. Oliveira (2016) ${ }^{4}$, deram abertura a um campo de pesquisas sobre Modelagem, constituindo-se uma comunidade de pesquisadores (BARBOSA, 2007) que depreendem interesses sobre esse tema.

Desde então, essas pesquisas têm exercido influências não só nas reflexões e produções, mas também intervindo no campo da formação de professores de Matemática. Segundo Fiorentini et al. (2016, p. 25), “[...] os principais contextos e dimensões de investigação do campo emergente de estudo do professor que ensina Matemática” tem sido a formação inicial, formação continuada, formação inicial/ continuada e outros contextos, bem como de "[...] aspectos relativos à vida, à prática, ao pensamento, aos saberes, às crenças, às concepções do professor que ensina Matemática, bem como do formador de professores" (FIORENTINI et al., 2016, p. 24), conforme registrou a pesquisa desenvolvida pelo Grupo de Estudos e Pesquisas sobre Formação de Professores de Matemática (GEPFPM) ${ }^{5}$. Ela sinalizou que, apesar de haver uma preocupação central com o sujeito - o professor - nas pesquisas em Educação Matemática, ainda “[...] há uma relativa preocupação com as licenciaturas e a pedagogia, além do interesse em projetos ou programas que acontecem durante a formação inicial” (NACARATO et al., 2016, p. 333), dentre eles “[...] Pibid, cursos EaD, Curso Normal, cursos de extensão ou cursos/projetos mais pontuais, como: modelagem matemática, uso das TIC, laboratório de ensino, cursos de serviço, Didática da Matemática, dentre outros" (NACARATO et al., 2016, p. 334).

Nesse contexto, as investigações no campo da Modelagem vêm avançando na medida em que ocorre a disseminação dos resultados decorrentes das pesquisas e também como reflexo das orientações para a prática docente nos documentos oficiais, como é o caso do Estado do Paraná, com as Diretrizes Curriculares da Educação Básica de Matemática (DCE). Atribuída a essa presença, novos rumos passaram a orientar as reflexões sobre Modelagem, "[...] redefinindo o perfil das investigações” (OLIVEIRA; KLÜBER, 2017, p. 182), quando a formação de professores passa a ser então uma temática nas e das investigações em Modelagem, convergindo para especulações sobre a Modelagem nos diferentes contextos, por exemplo, os emergentes da investigação realizada por Fiorentini, Passos e Lima (2016).

\footnotetext{
${ }^{3}$ Para fins textuais, utilizaremos apenas o termo Modelagem para nos referirmos à Modelagem Matemática na Educação Matemática.

${ }^{4}$ Um mapeamento sobre os eixos temáticos de pesquisa sobre Modelagem, bem como, uma agenda para pesquisa pode ser aprofundada na pesquisa realizada pela autora supracitada.

${ }^{5}$ A pesquisa desenvolvida pelo grupo e colaboradores foi coordenada pelo Prof. Dr. Dario Fiorentini, quando realizaram um mapeamento da pesquisa acadêmica brasileira, num período de 2001 a 2012, sobre o professor que ensina Matemática.
} 
Como pesquisadores desse campo (o da Modelagem), a temática formação de professores em Modelagem se mostrou relevante para desde a estruturação do trabalho de dissertação de mestrado do primeiro autor (OLIVEIRA, 2016), pois ela emergiu do exercício da prática docente enquanto docente-formador de professores e permanece desde então como inquietação que requer melhor compreensão, refletindo na produção de outras (novas) reflexões, como esse texto que apresentamos. Inquietação esta que tem nos alimentado, permitindo-nos compreendê-la (a formação de professores em Modelagem) mediante os seus diferentes modos de ser e de aparecer, isto é, mediante a sua multiplicidade de perfis (SOKOLOWSKI, 2004). O olhar sob esses perfis tem nos provocado várias interrogações e uma delas, ao ser aclarada, deu-nos abertura à investigação do tema a formação em Modelagem pelo Estágio Curricular Supervisionado Obrigatório $^{6}$. E perseguimos esse tema também na pesquisa de doutorado ${ }^{7}$.

Ao admitirmos a formação em Modelagem pelo Estágio como fenômeno de pesquisa, passamos a refletir sobre os modos pelos quais poderíamos compreendê-lo em direção às suas características e à sua essência. No movimento de nos perguntarmos quais caminhos deveríamos tomar, demo-nos conta de que clarear, inicialmente, a compreensão sobre a inserção da Modelagem no Estágio de modo abrangente, num sentido de compreender sobre as experiências com a Modelagem vivenciadas durante o Estágio, seja enquanto componente curricular no âmbito da universidade, seja na escola básica, seria relevante para caminharmos ao encontro dos sentidos que a ela (a compreensão) podem ser atribuídos e, ao mesmo tempo, sustentarmos como investigação essa formação que buscávamos compreender. Dessa tomada de consciência, um estudo que tematizava a compreensão de futuros professores sobre a inserção da Modelagem no Estágio pareceu-nos fazer sentido em ser realizado pela possibilidade de compreensões que dizem dessa inserção serem elaboradas, já que, para nós, só tem sentido investigarmos sobre essa formação se já compreendemos os aspectos que dão a ela a possibilidade de se mostrar como presença e/ou ausência.

Oriundo dessa clareza é que a elaboração deste texto se torna relevante, quando voltamos os nossos olhares, portanto, para essa compreensão sobre a inserção da Modelagem no Estágio, conforme já empreendemos nesse sentido mais abrangente. Contudo, entendemos que só tem sentido em falar de compreensão sobre essa inserção da Modelagem no Estágio se ela foi vivenciada, por entendermos que a compreensão sobre uma coisa se estabelece quando é experienciada, sentida, vivida, posta sob reflexão e expressa de algum modo.

Desse modo, ouvirmos aqueles que vivenciaram a experiência com a Modelagem no Estágio nos mostrou como possibilidade para refletirmos sobre a compreensão indicada por eles. Mesmo que essa compreensão possa parecer restrita à de alguns futuros professores na condição de estagiários, para nós, é reveladora de sentidos, os quais nos permitiram refletir de modo mais amplo ${ }^{8}$ sobre a inserção da Modelagem no Estágio. A experiência vivida a que nos referimos foi sistematizada durante um período por nós, enquanto docentes-formadores. Dessa forma, mostra-se como intencional e dirigida.

\footnotetext{
${ }^{6}$ A fim de evitar repetições, utilizaremos apenas o termo Estágio.

${ }^{7}$ Pesquisa, em desenvolvimento, da Tese de Doutorado do primeiro autor, orientada pela coautora deste texto.

${ }^{8}$ Modo mais amplo, porque uma primeira versão deste texto, apenas sinalizando as ideias que aqui são expostas, foi publicada na modalidade pôster, no V Seminário Internacional de Pesquisa e Estudos Qualitativos (SIPEQ), que ocorreu em 2018, na cidade de Foz do Iguaçu, no Estado do Paraná.
} 
Iluminados pela interrogação O que os estagiários que vivenciaram a inserção da Modelagem no Estágio compreendem sobre essa experiência?, este artigo nos mostra, portanto, alguns aspectos sobre essa inserção emergentes dos depoimentos de estagiários de um curso de Licenciatura em Matemática, de uma universidade estadual paranaense, ao vivenciarem a Modelagem no Estágio. No horizonte dessa investigação que apresentamos, os estagiários expressaram alguns significados sobre a inserção da Modelagem no Estágio que evidenciamos como oriundos do movimento que efetuamos e que passamos a descrever na seção seguinte.

\section{Postura de investigação e desdobramentos metodológicos}

Ao colocarmos em destaque as compreensões sobre a inserção da Modelagem no Estágio, voltamos os nossos olhares para elas e, na medida em que as percebemos como presença, mostrando-nos como fenômeno desta pesquisa, reconhecemos que o retorno a elas pode ser um caminho para desnudá-las, compreendê-las.

Ao assim procedermos, nos inserimos num movimento singular que pode ser compreendido na pesquisa qualitativa com um novo significado. Segundo Garnica (1997, p. 111), nesse movimento, o termo pesquisa admite novo significado, isto é, passa " [...] a ser concebido como uma trajetória circular em torno do que se deseja compreender, não se preocupando única e/ou aprioristicamente com princípios, leis e generalizações, mas voltando o olhar à qualidade, aos elementos que sejam significativos", a quem experiência. Do mesmo modo, Bicudo (2011) explicita que esse movimento também se expressa ao assumirmos uma interrogação, pois ele ocorre para que possamos perseguir o fenômeno, o qual se destaca como figura de um fundo.

Aquilo que desejamos compreender, o fenômeno, é manifesto da síntese noésis-noema, isto é, o ato de ver o visto, que ocorre desde o movimento da percepção, e que é colocado em evidência, dada a intencionalidade de quem o faz (BICUDO, 2011). No contexto desse estudo, podemos dizer que a vivência como docentes-formadores de Estágio e o trabalho de mestrado ao indicar-nos a possibilidade de práticas de Modelagem nesse contexto, nos revelou, portanto, a formação em Modelagem pelo Estágio. E ao refletirmos sobre os modos pelos quais deveríamos persegui-la, a compreensão sobre a inserção de atividades de Modelagem no Estágio foi destacada como fenômeno pela nossa consciência, por mostrar-nos um sentido em compreendê-lo, dada as suas relações com essa formação.

Admitindo que "fenômenos nunca são compreendidos sem que sejam inicialmente interrogados [...]" (GARNICA, 1997, p. 114), este estudo tem como interrogação de pesquisa O que os estagiários que vivenciaram a inserção da Modelagem no Estágio compreendem sobre essa experiência?, que, ao ser interrogada, mostrou-nos, como solo de manifestação, os depoimentos de estagiários que vivenciaram a Modelagem no Estágio. Os 19 estagiários participantes dessa pesquisa estavam matriculados nas componentes curriculares semestrais de Estágio II e IV, de um curso de Licenciatura em Matemática, quando se engajaram num processo formativo em/com Modelagem, no $2^{\circ}$ semestre de 2016, e desenvolveram as atividades propostas, coletivamente. As componentes curriculares de Estágio da universidade que faziam parte eram 
distribuídas em Atividades Teóricas e Atividades Práticas, sendo a segunda realizada em duas modalidades: o Estágio convencional e o Estágio não convencional ${ }^{9}$.

A experiência aqui referida remete à vivência dos estagiários no Estágio não convencional. Para essa modalidade, nesse caso particular, foi privilegiado um Estágio visando uma formação em Modelagem ao encontro do que propõem algumas orientações na literatura de Modelagem, isto é, agendando que essa formação deva "[...] se basear em duas frentes indissociáveis: a modelagem propriamente dita e o conhecimento prático decorrente de sua abordagem na sala de aula" (BARBOSA, 2001, p. 14); que “[...] requer aprendizados relacionados ao fazer modelagem, à preparação de situações de modelagem e à aplicação dessas situações em aulas da educação básica” (SILVA; DALTO, 2011, p. 182), e ainda que seja estruturada “[...] a partir da tríade 'aprender sobre', 'aprender por meio' e 'ensinar usando"' (ALMEIDA; SILVA; VERTUAN, 2013, p. 24).

Em linhas gerais, entendemos que a estrutura desse Estágio contemplou essas orientações, acontecendo em cinco encontros presenciais na universidade em que os estagiários vivenciaram na condição de estudantes o desenvolvimento de atividades fechadas e abertas. $\mathrm{O}$ entendimento por atividades fechadas e abertas repousa em Sant'Ana e Sant'Ana (2015), quando propuseram uma classificação para as questões inerentes às tarefas de Modelagem, a saber:

[...] questão aberta: aquela cuja resposta depende de hipóteses realizadas pelos estudantes, na qual mudanças de estratégia permitem a obtenção de respostas distintas; questão fechada: aquela cujos dados fornecidos são suficientes para a obtenção de resposta única, com uma estratégia vinculada à sua formulação, que coincide com o que Freire e Faundez (1985) chamam de "pergunta burocrática"; questão semifechada: aquela que tem formulação semelhante à questão fechada, mas permite, por meio de subitens, reformulação de estratégias com vistas ao questionamento da exatidão da resposta (SANT'ANA; SANT'ANA, 2015, p. 4, grifos nossos).

O envolvimento com essas tarefas de Modelagem foi garantido de forma gradativa, de acordo com o (des)envolvimento dos estagiários com elas. Organizados em grupos, a dinâmica adotada era a de que cada grupo deveria encontrar soluções para as situações-problema propostas e, em seguida, deveria apresentá-las ao grande grupo. No decorrer dos encontros, fomos propondo atividades mais abertas em que, no término de cada um deles, sempre discutíamos as características das atividades, os encaminhamentos adotados e as possíveis relações/ diferenciações com as demais atividades já desenvolvidas e também com outras tendências em Educação Matemática conhecidas pelos estagiários. Discutíamos quais conteúdos eram e poderiam ser abordados a partir das atividades, o modo como cada grupo apresentava e discutia os resultados, e direcionávamos o debate para as possibilidades e dificuldades ao orientar

\footnotetext{
${ }^{9}$ O Estágio convencional faz alusão às experiências de Estágio como diagnóstico e intervenção na realidade escolar, enquanto que o não convencional, se caracteriza pelo desenvolvimento de atividades experimentais e suporte a estudantes com dificuldades de aprendizagem.
} 
a prática pedagógica com Modelagem na sala de aula. No último encontro, apresentamos algumas reflexões inerentes à literatura de Modelagem, quando foi possível estabelecermos um paralelo com os encaminhamentos adotados pelos estagiários durante o desenvolvimento das atividades propostas nos encontros anteriores.

Em um segundo momento solicitamos aos grupos de estagiários o planejamento, sob nossa orientação, de uma atividade de Modelagem que foi implementada em uma turma, na Educação Básica. Para isso, pesquisaram algumas atividades propostas na literatura de Modelagem (relatos) e, em momentos de planejamento, foram realizadas as discussões de algumas ideias, de possíveis adaptações, bem como os modos pelos quais as atividades escolhidas poderiam ser implementadas, segundo os objetivos por eles estabelecidos. $\mathrm{Na}$ ocasião, discutimos possíveis circunstâncias da prática pedagógica, conforme as especificidades das atividades escolhidas pelos grupos e como eles poderiam lidar com elas, almejando a aprendizagem dos estudantes.

No terceiro momento, cada um dos grupos implementou, na Educação Básica, na condição de professores-estagiários, a atividade que foi planejada, quando foi possível vivenciarem a prática da Modelagem com os estudantes desse nível de ensino (anos finais do ensino fundamental e ensino médio). Como as implementações aconteceram em horários e dias alternados, nós pudemos acompanhá-los dando o suporte que precisavam e, ao término das implementações, ainda no colégio, cada um dos grupos de estagiários foi convidado ao momento de discussão e reflexão sobre a vivência que tiveram com aquele Estágio, refletindo, desde as atividades propostas na universidade até aquelas que haviam acabado de vivenciar. Quando nos referimos à vivência, não a entendemos como algo dado, mas como o "[...] sentido de experiência vivida, dizendo, com isso, do contato imediato com a vida, não se tratando de um conteúdo de experiência, mas do ato de vivê-la" (BICUDO, 2011, p. 33), podendo nos revelar a compreensão que os estagiários estabeleceram nesse fluxo das vivências, sobre a inserção da Modelagem no Estágio.

Desse engajamento, com autorização dos estagiários, foi possível reunirmos os depoimentos dos participantes, os quais foram gravados em áudio, transcritos e inseridos no software de análise qualitativa de dados, denominado Atlas t.i.. No software, ao admitirmos o movimento de busca por ir-à-coisa-mesma, realizamos várias leituras ao destacarmos unidades de sentido, isto é, excertos que diziam de algum modo sobre os aspectos significativos à interrogação que nos iluminava. Na sequência, essas unidades foram reunidas, conforme a convergência dos seus sentidos e dando-nos abertura ao que denominamos de núcleos de sentidos.

Apresentaremos os dois núcleos emergentes dessa convergência entre os sentidos no quadro 1.

Quadro 1 - Núcleos de sentidos emergentes

\begin{tabular}{|l|l|}
\hline Descrição & Núcleo \\
\hline $\begin{array}{l}\text { O núcleo diz das compreensões dos estagiários quanto à inserção de } \\
\text { atividades de Modelagem no Estágio como componente curricular. }\end{array}$ & $\begin{array}{l}\text { N-1 - Modelagem no contexto } \\
\text { do Estágio }\end{array}$ \\
\hline $\begin{array}{l}\text { Esse núcleo expressa reflexões dos estagiários sobre levar ou não, } \\
\text { atividades de Modelagem na realização do Estágio, nos colégios- } \\
\text { campo. }\end{array}$ & N-2 - Estágio com Modelagem \\
\hline
\end{tabular}

Fonte: elaborado pelos autores. 
Expostos os núcleos de modo breve, nesse momento, passamos a descrevê-los. A “[...] descrição torna-se ponto chave da pesquisa qualitativa fenomenologicamente conduzida [...] [pois] descreve, diz do ocorrido como percebido" (BICUDO, 2011, p. 38), isto é, diz da vivência dos estagiários com a inserção da Modelagem no Estágio, refletida na compreensão deles sobre essa inserção. $\mathrm{O}$ dito por eles foi articulado por nós, para que então pudéssemos tecer algumas reflexões sobre essa inserção, mediante a compreensão dos estagiários.

Quanto ao movimento de descrição, em relação ao N-1 - Modelagem no contexto do Estágio descrito a seguir, este expressa o que os estagiários compreenderam sobre a presença da Modelagem durante o Estágio enquanto componente curricular da Licenciatura em Matemática. Demos destaque (em negrito) para alguns dos excertos desse articulado, por darem sentidos às reflexões que empreenderemos na sequência, o que não significa que tenham sido tomados isoladamente.

\section{Descrição do Núcleo N-1}

O modo pelo qual a Modelagem foi desenvolvida no Estágio "foi bacana", algo novo, bem melhor do que outras experiências de Estágio, diferente do que foi vivenciado em outras componentes. Permitiu com que estudassem, realizassem algumas atividades no papel de estudantes, utilizando recursos da Matemática para criar modelos, e também como professores trabalhando com Modelagem, ao implementarem uma atividade. Até então, só haviam vivenciado como estudantes, aprendendo com Modelagem. O Estágio foi válido porque tiveram contato com atividades tomadas de perspectivas diferentes, dentre elas, as mais abertas e nada direcionado como de costume.

Para alguns, foi o primeiro contato com Modelagem, enquanto que para outros, foi oportuno para mudarem a compreensão sobre Modelagem, de que se resumia à entrega de uma "folbinha", em que se lia um texto e tinha um "probleminha". A vivência permitiu saberem que envolve muitas outras coisas. Compreendiam que Modelagem não tinha uma resposta certa ou errada, então não era apropriada para se trabalhar na Educação Básica. Mas, ao engajarem-se no Estágio, puderam conhecer a que se refere esse certo e esse errado. A obrigatoriedade da implementação forçou-os a explorarem algo que de repente os estagiários não fariam por ser mais confortável realizar outra atividade que não de Modelagem, o que oportunizou aprendizagens com e a partir da prática. Emerge dai o trabalho em grupos, permitindo que as dúvidas pudessem ser sanadas entre eles, conseguindo conversarem, inclusive nos planejamentos, quando discutiam o que pensar ao montar uma atividade. Sem aqueles momentos de sentar, discutir, em que as ideias surgiam para elaborarem a atividade, teria sido mais difícil. A prática foi um desafio, surgiram várias dúvidas, mas que juntos dos docentes-formadores, foram sanadas. Foi um avanço significativo, caracterizando essas discussões como "chave de ouro".

Ao implementarem, tiveram uma noção do que é a Modelagem na sala de aula, que por sinal, apontaram ser bem diferente na prática, e que essa compreensão só foi possivel por conta do Estágio. Ainda não tinham sido professores e, durante o Estágio, aprenderam como abordar os temas, os alunos, que o espírito de questionar, instigar sem responder e nem encaminhar é a forma como deveriam conduzir. Vendo esse encaminhamento, parecia ser fácil, mas chegando à sala de aula foi um choque. Atrelada à experiência de ter os docentes-formadores questionando, agora sabem mais ou menos como conduzir, pois, com o Estágio, puderam ter uma visão mais prática de Modelagem, o que para realização de outras atividades, pode ser mais fácil.

Como foi uma primeira experiência, existem coisas a melhorar e não descartam a possibilidade de algumas ainda saírem erradas, ao utilizarem a Modelagem. O que é importa é que sempre aprendem com as experiências, mesmo naquelas situações em que fogem do controle, tudo o que fizeram acrescenta à formação e vai ajudar nos próximos Estágios ou na própria turma de Estágio. A experiência deu mais maturidade, que contribui para formação acadêmica e para a vida. 
Essas experiências relatadas acima oportunizaram aos estagiários a vivência da prática com Modelagem na sala de aula. Esse contexto deu abertura para refletirem sobre a adoção de atividades de Modelagem na realização do Estágio, que, no escopo desta investigação, constituíram o núcleo N-2 - Estágio com Modelagem, descrito a seguir. A descrição desse núcleo expressa, de modo geral, as compreensões dos estagiários sobre a realização do Estágio com Modelagem, tanto na modalidade convencional, quanto no não convencional.

\section{Descrição do Núcleo N-2}

\begin{tabular}{|c|}
\hline 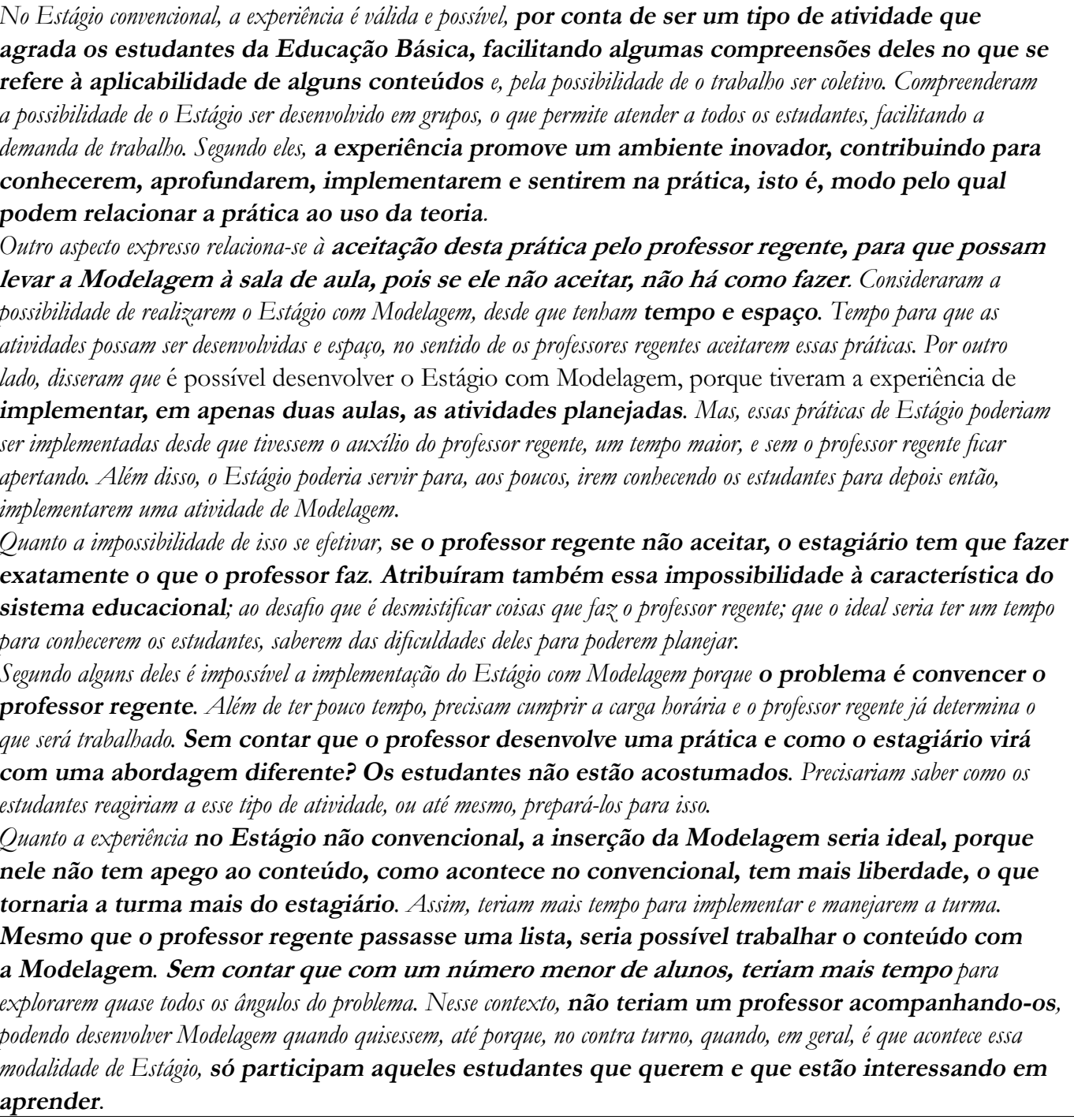 \\
\hline
\end{tabular}

Exposta a descrição de ambos os núcleos, sabemos que ela “[...] é sempre explicitada pela linguagem e é, por isso, que solicita análise e interpretação efetuadas com auxílio dos 
recursos hermenêuticos [...] [voltando o] foco nos aspectos culturais e históricos" (BICUDO, 2011, p. 38-39), do fenômeno contextualizado, para que, dessas descrições, possam ser estabelecidas compreensões daquilo que se mostra do fenômeno em destaque. Como se articula por meio da linguagem, nesse caso a escrita, recorremos ao enxerto hermenêutico, que, para Hermann (2002, p. 24), “[...] carrega consigo a ideia de tornar explícito o implícito, de descobrir a mensagem, de torná-la compreensível [...]”. É esse o movimento intencional, de tornar compreensível a compreensão sobre a inserção da Modelagem no Estágio que admitimos e que deu abertura a algumas interpretações e reflexões, quando olhamos de modo atento para essas descrições à luz do que interrogamos.

Fazendo referência à pesquisa fenomenológica, entendemos que a postura adotada se insere no movimento que conhecemos por epoché (BICUDO, 2011). Ao buscarmos clarear o que se mostra, colocamos em suspensão nossos conhecimentos prévios, desde o destaque das unidades até o momento de efetuarmos esse movimento de interpretação, estendendonos à compreensão sobre o dito. Em outras palavras, entendemos que várias reduções foram efetuadas ao operarmos de modo intencional, colocando assim em evidência aquilo que se mostra, sem pré-julgamentos. Desprezamos as lentes pelas quais poderíamos olhar para os dados emergentes, tomá-los como unidades, categorizá-las e discuti-las com base em algum referencial teórico. Queremos dizer que o movimento admitido buscou, à luz da interrogação de pesquisa $O$ que os estagiários que vivenciaram a inserção da Modelagem no Estágio compreendem sobre essa experiência?, analisar os sentidos expressos e os possíveis significados que a eles podem ser atribuídos, no que se refere às compreensões sobre a inserção da Modelagem no Estágio.

Exposto o modo pelo qual consideramos os dados que dizem do fenômeno em destaque, passaremos às reflexões que se revelaram como compreensão sobre a inserção da Modelagem no Estágio.

\section{Sobre a inserção da Modelagem no Estágio: interpretando e refletindo os discursos articulados}

Iniciemos justificando que o empreendido nesta seção faz referência às compreensões sobre o articulado de ambos os núcleos, as quais puderam ser estabelecidas sobre o fenômeno em questão, considerando a nossa interrogação de pesquisa, O que os estagiários que vivenciaram a inserção da Modelagem no Estágio compreendem sobre essa experiência?. Nesse sentido, a nossa opção foi que, ao invés de tomarmos cada um dos núcleos separadamente, para essa discussão, alinhavamos, em num único escrito, as compreensões sobre a inserção da Modelagem no Estágio, oriunda do entrelaçamento de ideias manifestadas de ambos, voltando nossos olhares para o fenômeno dirigido.

Dessa relação possível, que nos mostra o sentido da pesquisa, revelou-nos que, embora os estagiários compreendessem algumas potencialidades da Modelagem no contexto do Estágio (emergente das descrições que foram articuladas), as quais puderam ser reconhecidas por eles mediante a experiência vivida com a Modelagem, ainda pareceram ser receosos à abordagem do Estágio com Modelagem, como prática pedagógica na Educação Básica.

Essa compreensão se sustenta pelo fato de que os estagiários compreenderam que a Modelagem no Estágio "foi bacana", "algo novo, bem melhor do que outras experiências de Estágio", diferente do que foi vivenciado em outras componentes, isto é, comparada com outras experiências 
que tiveram, em outras componentes curriculares, a vivência com esta se destacou. Isso mostra que, nessa abordagem, os estagiários identificaram um sentido para a Modelagem na sua formação e, talvez, isso esteja relacionado ao modo pelo qual as atividades foram sendo conduzidas e desenvolvidas.

Eles só haviam vivenciado atividades de Modelagem como estudantes, e essa experiência, na qual atuaram como professor trabalhando com Modelagem, mostrou-lhes outra forma de vivenciá-la que, certamente, contribuiu para agendarem essa reflexão. Tanto que, para alguns, a tomada de consciência sobre o vivido revelou a Modelagem como uma nova possibilidade metodológica, ao provocar mudanças de compreensão do que era a (prática com) Modelagem. Essa nova possibilidade parece estar condicionada à reavaliação da Modelagem como proposta metodológica para a prática pedagógica na Educação Básica, condicionada à experiência vivida e refletida.

Podemos dizer que a inserção da Modelagem no Estágio se mostrou, num primeiro momento, como um embate para os estagiários, dada a visão distorcida que alguns deles tinham sobre os aspectos que podem caracterizar a Modelagem e a sua prática. (In)compreensões estas que foram suficientes para decidirem em não adotá-la, por exemplo, pelo fato de trabalharem com problemas que não possuem, necessariamente, uma única resposta correta. Nesse contexto, o que não compreendiam, e que as práticas realizadas no Estágio possibilitaram compreender, é que a metodologia da Modelagem, enquanto alternativa/ estratégia/ ambiente de aprendizagem, é incompatível com as ideias fixas, prontas e acabada e, sim, dependente das hipóteses que são estabelecidas para chegarem às conclusões da situação que é problematizada como tarefa ou atividade nesta prática.

Essa mudança de compreensão que pôde ser estabelecida no contexto da experiência vivida pelos estagiários expressa, portanto, o sentido atribuído à formação que, por sua vez, está condicionada a essa inserção, tendo a reflexão como mediadora na produção de conhecimentos sobre a docência em/com Modelagem. Ademais, ela pode ser resultante do esforço empreendido e já vislumbrado pela literatura de que o (futuro) professor deve

[...] ter a oportunidade de refletir sobre as experiências com modelagem no contexto escolar: como organizaram, que estratégias utilizaram, que dificuldades tiveram, de que forma os alunos reagiram, como foi a intervenção do professor etc. A reflexão sobre estas vivências possibilita aos professores a geração de conhecimentos que possam subsidiar suas práticas pedagógicas com modelagem (BARBOSA, 2001, p. 9).

Destacamos o papel importante que esses momentos têm para a formação do futuro professor, pois, mesmo que possam parecer episódicos, é evidente que podem provocar insights que auxiliam na compreensão sobre determinados aspectos, ainda obscuros ou confusos aos (futuros) professores. Transitivamente, a clarificação sobre eles transcende nos saberes da prática docente, refletindo desde o planejamento à ação pedagógica em sala de aula. Com a experiência da Modelagem, o insight se manifestou por esse movimento de reflexão, explícito no confronto entre o modo pelo qual os estagiários concebiam a prática com Modelagem em sala de aula e a própria experiência vivida por eles com a Modelagem no contexto do Estágio e o Estágio com Modelagem. 
Essa discussão nos convida a refletirmos sobre o modo pelo qual a formação ${ }^{10} \mathrm{em}$ Modelagem vem sendo realizada. Ao mencionarem também que as atividades não foram direcionadas como de costume, mostra que já tiveram algum contato com a Modelagem, tanto é que sustentavam algumas (in)compreensões. Talvez, o modo pelo qual conheceram sobre Modelagem deixou algumas lacunas que, possivelmente, gerenciaram essas visões. Com isso, não se trata de fazermos uma apologia à inserção da Modelagem no Estágio, mas de evidenciarmos que esse contexto pareceu fazer mais sentido para os estagiários quanto às aprendizagens sobre Modelagem, ao dizerem que, com essa experiência, puderam ter uma noção da Modelagem (e sua prática) na sala de aula. Diante disso, instaurou-se a seguinte indagação: o que havia (para os estagiários) antes dessa experiência sobre a Modelagem?

Essa tomada de consciência, oriunda do movimento de reflexão do dar-se conta de..., evidenciou para nós o olhar crítico que os estagiários tiveram para sua própria formação. Olhar este que se volta para o próprio docente-formador na universidade, que, muitas vezes, pode se tornar espelho para o futuro professor, influenciando-o na adoção ou negação de algumas abordagens para o ensino, bem como aquela compreensão estruturada pela sua caminhada escolar. Essas influências podem ser vislumbradas na própria descrição expressa, quando mencionaram que a "obrigatoriedade de implementarem uma atividade na Educação Básica forçou-os a explorarem algo que de repente os estagiários não fariam por ser mais confortável realizar outra atividade que não de Modelagem".

O forçou-os, termo utilizado pelos estagiários, tem relação direta ao que alguns estudos da literatura nos mostram sobre o sair da zona de conforto e ir para a zona de risco (PENTEADO, 2001), exigindo reorganização da prática pedagógica, ao saírem da postura de detentores do conbecimento para orientadores, mediadores do processo de ensino e aprendizagem. À luz da interrogação, o Estágio consistiu como um momento singular, que oportunizou aprendizagens com e a partir da prática, na medida em que os estagiários se aventuraram. Mostrou-se, nesse sentido, ser um espaço e tempo em que se dispuseram para conhecer, experimentar, refletir, reorganizar, (re)experimentar, enfim, ousar em diferentes abordagens, revelando-o como imprescindível e oportuno para a construção do estofo pedagógico, momento este que é garantido pela formação inicial (OLIVEIRA, W.; KLÜBER, 2015).

Por essa razão, ao vivenciarem o Estágio com Modelagem na condição de professores, a reflexão nos mostra que não só indícios de aprendizagens sobre Modelagem, como algumas das indicadas por Braz (2017) e sua prática foram evidenciadas, mas também foi um primeiro passo para os estagiários agendarem outros estudos e/ou novas práticas de Modelagem, revisitando as fragilidades, reelaborando, adaptando e, assim, ampliando o conhecimento teórico-prático sobre Modelagem. Isso porque, nesse movimento de planejar, ir a campo e refletir sobre o processo com Modelagem, sobretudo, as discussões/orientações em grupo foram consideradas pelos estagiários como chave de ouro, que permitiram a ressignificação dos conhecimentos e da compreensão que tinham sobre essa Tendência. Agendamos esse movimento como relevante para o momento da formação, principalmente, por ser esse o papel do Estágio,

\footnotetext{
${ }^{10}$ Estendendo-nos nessa compreensão, talvez como agenda, ela nos dá abertura à visualização de outros aspectos dessa inserção, os quais podem auxiliar na compreensão sobre a formação em Modelagem.
} 
o de experienciar e investigar práticas, em busca da compreensão do trabalho pedagógico, mediante a análise e problematização delas (PIMENTA; LIMA, 2004).

Quando refletimos sobre o termo chave de ouro utilizado pelos estagiários, uma interpretação que se abre é que a chave diz de um instrumento para abrir portas e o ouro, elemento de valor que expressa riqueza. Assim, a compreensão que se mostra sobre a inserção da Modelagem no Estágio pode ser interpretada como sendo essa inserção um modo pelo qual é possível vivenciar a Modelagem, que se expressa em uma diversidade de aspectos para a formação do futuro professor. Rica por contemplar diferentes encaminhamentos e ser conduzida pelo diálogo e pela reflexão sobre/com/e a partir da prática de Modelagem.

A vivência com essa prática na condição de professores-estagiários parece sobressair a outras experiências que tiveram com Modelagem. A noção sobre a prática oriunda da experiência que os estagiários tiveram indica-nos que ainda há necessidade de outras experiências para uma compreensão mais plena da Modelagem, tanto sobre seus aspectos epistêmicos quanto sobre os pedagógicos. Deixemos claro que isso não quer dizer que os compreendemos como separáveis. Ao que nos mostra, essa noção emergente é atribuída a essa inserção, modo pelo qual os estagiários puderam recontextualizar a prática de Modelagem ao realizarem o Estágio com Modelagem, a partir da experiência que tiveram com ela no contexto do Estágio. Entendemos que a ação de recontextualizar pode ser interpretada como uma recontextualização pedagógica, numa acepção à teoria de Bernstein (2000), quando os estagiários dão indícios do como poderiam mover para um contexto pedagógico com Modelagem, os discursos produzidos e os modos de encaminharem as atividades de Modelagem à luz da postura admitida pelos docentes-formadores, na vivência com a Modelagem no contexto do Estágio.

No entanto, por mais que essa experiência pôde ser enriquecedora, como expressaram os próprios estagiários quando foram realizar o Estágio com Modelagem, o contato com a sala de aula foi para alguns deles um choque. Isso mostra que, por mais que se engajaram num movimento de formação, em alguns momentos, a prática pode consistir num embate, desestruturando-os, colocando o futuro professor em situações de imprevisibilidade, na qual precisa agir indicando o modo pelo qual os estudantes devem se envolver com a atividade. Atividade esta que exige um modo de pensar e um caminho a perseguir para ser desenvolvida, que nem o professor-estagiário e, raramente, os estudantes estarão habituados.

Esse comportamento parece ser comum nos primeiros passos, quando tomam a decisão de inserirem-se na zona de risco e, por essa razão, revela o potencial de situações como essa que empreendemos no momento da e para a formação, ao caracterizarem-se como momentos (MOURA, 1989) ${ }^{11}$ da formação, que propiciam maturidade ao futuro professor. Entendemos por maturidade, no contexto desse estudo, o aspecto de amadurecimento das experiências pedagógicas com Modelagem que essa inserção da Modelagem no Estágio parece oferecer, isto é, os estagiários parecem vislumbrar que essa inserção propicia situações que dão a eles condições de refletirem e, ao mesmo tempo, amadurecerem-se como profissionais no que

\footnotetext{
${ }^{11}$ Segundo o autor, momentos são compreendidos como partes dependentes e que constituem um todo. 
se refere ao trabalho pedagógico com Modelagem. Aspecto este que transcende, portanto, à formaça em Modelagem.

As reflexões sobre essa inserção também nos mostraram que alguns estagiários pareceram compreender a possibilidade de desenvolverem o Estágio com Modelagem, mas isso não significa a sua incorporação imediata. Essa possibilidade pode ser evidenciada da experiência que tiveram com as práticas vivenciadas por eles, pois, ao concluírem que atividades de Modelagem agradam e facilitam a compreensão dos estudantes, compreendemos que essas conclusões emergiram da atribuição de sentidos que as experiências tiveram para os estagiários, mediante as atividades que (des)envolveram tanto na universidade como na sala de aula na Educação Básica.

Essa atribuição torna-se mais evidente quando dizem do ambiente inovador que essa inserção propicia, ao poderem relacionar a prática ao uso da teoria. Ora, não é esse o sentido que as práticas supervisionadas de Estágio têm por um dos seus objetivos? Ao que tudo indica, a inserção de atividades de Modelagem no Estágio parece contribuir para superar essa dicotomia entre dois elementos que, na nossa compreensão, são essenciais e complementares sobre o dar sentido à formação do professor.

Embora essas experiências sinalizem compreensões favoráveis, a sua inserção parece ser um desafio por conta dos vários aspectos que dificultam a opção de orientar a prática pedagógica no Estágio, pelos pressupostos teóricos da Modelagem. Esses aspectos dizem da aceitação do professor regente, do tempo e do espaço para o desenvolvimento das atividades e dos aspectos didáticos e estruturais que regem o ambiente escolar, decisivos na abertura à realização das práticas de Estágio com Modelagem.

Não ocultamos que esses aspectos nos causaram certo desassossego. Primeiro, que o fato de ter que convencer o professor regente indica uma ação dirigida ao outro, que parece ir de encontro com o explicitado nos documentos norteadores, como as DCEs no Estado do Paraná, que trazem como orientações as Tendências Metodológicas para as práticas pedagógicas no ensino de Matemática. E, segundo, que o termo convencimento, ao mesmo tempo que pode indicar a distância do professor a essas abordagens, indica a resistência dele, pois, na medida em que o estagiário precisa convencê-lo, a ação indica insistência para poder realizar aquilo que pode ser considerado novo, diferente, inusitado. Sendo assim, essa manifestação revela-nos o distanciamento que ainda tem a Modelagem da sala de aula e, ao mesmo tempo, a presença explícita da zona de conforto de alguns professores. Não se trata de um julgamento, até porque reconhecemos os diferentes obstáculos que configuram as práticas escolares como, por exemplo, os citados na pesquisa de Ceolim (2015).

Ainda assim, parecem não dar importância às experiências que o Estágio pode propiciar sob uma via de mão dupla: o estagiário imerso naquele contexto para dedicar-se à aprendizagem dos estudantes e, ao mesmo tempo, na perspectiva do ensino, à sua aprendizagem como docente; e os professores-regentes, a oportunidade de firmarem parcerias com os estagiários e as universidades, tendo em vista sua formação continuada, conivente para refletirem sobre seus conhecimentos didático-metodológicos, concepções teórico-práticas, entre outros. Instaurar-se-ia um movimento de feedback, pois a Modelagem, ao mesmo tempo que seria transcendente à prática docente, orientada por estagiários e professores-regentes, seria instrumento de reflexão teórico-prática na universidade, ao ser retomada junto a eles com o docente-formador. Assim, circularmente, (re)alimentaria um coletivo de práticas que, baseado nas 
compreensões explicitadas por Klüber $(2012)^{12}$, gerenciado pela atuação de estagiários, professores-regentes e docentes-formadores, atribuindo sentido em serem planejadas, colocadas em prática na sala de aula e, assim, contribuindo para que, de algum modo, o trabalho pedagógico com a Modelagem chegasse às salas de aula na Educação Básica. Pode parecer óbvio, mas esse movimento merece atenção especial por ter como gênese a formação inicial e continuada em Modelagem de professores de Matemática.

Porém, o desassossego mencionado também se encontra na incomensurabilidade que há entre o sistema educacional e a Modelagem, emergente como compreensão dos estagiários, quando inferem sobre os desafios de sua inserção. Do mesmo modo, a “[...] estrutura educacional com currículo partido em várias disciplinas, cada disciplina sob a responsabilidade de um professor e horários e períodos para cumprir cada fase escolar, sem dúvida, é a principal dificuldade" (BIEMBENGUT; FARIA, 2009, p. 10.102), para que a Modelagem seja adotada como ferramenta que auxilia no processo de ensino e aprendizagem, nas aulas de Matemática. Compreendemos que a postura dos professores e a própria dinâmica do sistema educacional parecem ser fatores determinantes da carência dessas práticas nas salas de aulas, que, por sinal, trazem implicações na formação de outros professores (os em formação inicial), a começar pelas práticas que, no contexto dessa investigação, parecem ser coibidas (as práticas de Estágio com Modelagem, por exemplo), além de outras atividades de docência, na formação inicial.

Mesmo diante desses obstáculos, o N-2 nos mostrou que, embora alguns estagiários tenham destacado inúmeros percalços para realização do Estágio com Modelagem, evidenciaram que, no Estágio não convencional, a experiência seria ideal porque nesta modalidade eles têm mais liberdade para desenvolverem atividades e se dedicarem de modo mais efetivo às dificuldades dos estudantes, em direção à aprendizagem.

Por um lado, esse não descartar a possibilidade de desenvolverem práticas de Modelagem no Estágio não convencional pode estar relativizado no contexto. Entendemos que esse relativismo pode sinalizar dois aspectos: (i) que os estagiários ainda não têm clareza sobre a prática da Modelagem e acabam reproduzindo um discurso resumido nos obstáculos e dificuldades sobre a inserção da Modelagem na sala de aula (CEOLIM, 2015); (ii) que os estagiários se sentem mais confortáveis para o desenvolvimento de práticas de Modelagem, quando o professor-regente está ausente.

Esse desconforto evidente pode estar relacionado a $n$ motivos. Talvez, por acharem que não possuem conhecimentos suficientes da metodologia ou talvez pelas próprias especificidades que a turma pode apresentar em relação ao tipo da atividade, já que compreendem a necessidade de os estudantes estarem habituados a esse tipo de atividade, para que o trabalho aconteça de modo mais efetivo, quando envolvem metodologias/propostas diferenciadas.

Por outro lado, esse desconforto também pode indicar a própria compreensão que tem o estagiário sobre o processo de Estágio. O fato de o Estágio ser supervisionado, com a presença do professor-regente na sala de aula, parece figurar para eles uma situação constrangedora que acaba por influenciar no modo pelo qual poderiam conduzir a prática pedagógica.

\footnotetext{
${ }^{12}$ Conforme o autor supracitado, o entendimento que temos por coletivo de práticas, também pode ser uma tentativa de aproximação entre ambos os coletivos, o da Modelagem e o da formação de professores.
} 
Assim, o sentido da prática supervisionada acaba fugindo dos objetivos do Estágio, que, na concepção dos estagiários, parece resumir-se à avaliação do modo pelo qual dão conta do conteúdo utilizando a Modelagem ou lidam com o comportamento dos estudantes e não a aprendizagem, a reflexão sobre os saberes e os conhecimentos da Modelagem e da própria docência, que os permitem (res)significar suas compreensões com o desenrolar da experiência.

Destacamos que essa ressignificação é importante e preocupante. Importante porque, mesmo que o modo pelo qual sistematizamos a inserção de atividades de Modelagem no contexto do Estágio possa parecer comum na formação em Modelagem, ela nos dá indícios de que, para esses estagiários, foi relevante, pois permitiu a ressignificação do conhecimento sobre Modelagem e da sua prática. Porém, ao mesmo tempo é preocupante porque a palavra ressignificar nos faz refletir: se os estagiários não tivessem planejado e vivenciado a experiência da Modelagem no Estágio, quando fariam? Quando seria possível (res)significarem? E mais, quais as chances de não terem vivenciado essa experiência e a Modelagem chegar, efetivamente, na sala de aula quando professores? Esses questionamentos têm relação estreita com o precedente, no que se refere à noção sobre Modelagem que os estagiários tinham.

Concordamos que, com a Modelagem no Estágio, não significa que os estagiários vão de imediato desenvolver práticas com Modelagem, até porque seria uma ingenuidade conjecturarmos que isso daria conta da complexidade da prática docente. Mas, certamente, essas experiências despertaram novos entendimentos sobre Modelagem e sua prática, que, em algum momento, permitirão aos estagiários explorarem territórios que, talvez, antes nunca tivessem imaginado. Por essa razão é que concordamos com Tambarussi e Klüber (2017, p. 857), quando destacaram a importância de "se dedicar aos professores em formação inicial ou continuada de todos os níveis de ensino, para que as propostas educacionais não se restrinjam aos documentos, mas que possam ser exaustivamente discutidas e, se pertinentes, colocadas em prática", no que se refere aos investimentos na formação de professores. Nesse sentido, os discursos articulados por essa e outras investigações evidenciam que as experiências vividas por esses estagiários precisam ser fortalecidas e, como projeto na instituição, temos especulado sua permanência e colocado em prática até o presente momento, acontecendo sempre no segundo semestre do ano letivo.

Em linhas gerais, ambos os núcleos nos mostraram que as compreensões dos estagiários que vivenciaram essa experiência sobre a inserção da Modelagem no Estágio sustentam duas posições, que, embora pareçam ser complementares, uma se distancia da outra em termos de significados expressos pelos discursos. Colocando essas experiências na balança, a inserção da Modelagem no contexto do Estágio demonstra, na compreensão dos estagiários, inúmeras contribuições à formação do professor que, inclusive, por ser um momento de contato com o ambiente escolar, agora no papel invertido de estudantes para professores-estagiários, potencializa reflexões que, em outros momentos, não teria a mesma profundidade sobre os processos de ensino e aprendizagem da Matemática com a Modelagem, a mudança de atitude favorável a esses processos, a própria realidade escolar, entre outros aspectos que constituem esse contexto.

Entretanto, ao mesmo tempo, essa inserção se mostra como um embate no tocante às experiências nos colégios-campo, pois parece estar consolidada nas práticas que vêm sendo desenvolvidas pelos estagiários, um descompasso entre o que se propõe no contexto universitário e a realidade da escola básica. Esse embate pode ser compreendido como explicitado por 
Pimenta e Lima (2004), em um Estágio ainda baseado na imitação de modelos ou instrumentalização técnica, isto é, quando se pensa nessa inserção, parecem desapoiar a adoção de metodologias diferenciadas, ao direcionarem as práticas dos estagiários àquilo que, muitas vezes, contribui para a perda do verdadeiro sentido do termo pedagógico nas ações. Para além do alerta, insistimos no convite a reflexões sobre o modo pelo qual essa inserção da Modelagem e de outras Tendências Metodológicas ${ }^{13}$ têm ocorrido no Estágio, despertando-as como temas de projetos e parcerias entre as universidades e os colégios-campo, motor para a aprendizagem dos coletivos eminentes envolvidos.

\section{Considerações finais}

As reflexões que empreendemos nesse manuscrito convergem para o que temos defendido como pesquisas endereçadas à perspectiva formativa da Modelagem, ao visar a formação dos estagiários no planejamento e desenvolvimento de algumas ações e por interrogar a compreensão deles sobre essa inserção, tangenciando reflexões sobre a dimensão formativa dessas experiências. Reflexões estas que são inerentes aos aspectos “[...] epistemológicos próprios [da Modelagem], os quais solicitam conhecimentos particulares, entre os quais situações práticas, didáticas, pedagógicas, cognitivas e outras [...]” (OLIVEIRA, 2017, p. 518) são mobilizadas no debate sobre a formação em Modelagem, muitas vezes, secundárias às práticas (e pesquisas) já consolidadas na e para a formação, por exemplo, no contexto do Estágio.

Ao retomarmos a interrogação que nos move: $O$ que os estagiários que vivenciaram a inserção da Modelagem no Estágio compreendem sobre essa experiência?, empreendemos que a compreensão dos estagiários sobre a inserção da Modelagem no Estágio se orienta pelo reconhecimento de sua relevância para a promoção de práticas e importância para a formação, porém reside também na compreensão dos desafios que se impõem para sua efetiva inserção em sala de aula. $\mathrm{O}$ Estágio como um campo de produção de conhecimentos teórico-práticos sobre Modelagem se destaca, mas ainda está fadado às limitações que o próprio contexto vivido oferece como condição para a realização do Estágio.

No entanto, entendemos que, dos possíveis significados expressos no desenvolvimento deste estudo, se relacionarmos o contexto, os objetivos das atividades que foram desenvolvidas e os objetivos do próprio encaminhamento de trabalho com a inserção da Modelagem no Estágio, o estudo também nos aponta sobre a relevância das práticas no âmbito da formação inicial, para que possamos superar seu quadro atual na licenciatura em Matemática, dado ao nível de intensidade e engajamento (TAMBARUSSI; KLÜBER, 2017) com que foram vivenciadas.

Nesse sentido, para além das compreensões empreendidas, nossas reflexões sobre os dados nos revelam que, quando as práticas ocorrem de modo assistidas, orientadas e, acima de tudo, refletidas, podem encorajar os futuros professores a buscarem conhecimentos

\footnotetext{
${ }^{13}$ Tendências metodológicas em educação matemática, a saber: etnomatemática, história da matemática, investigação matemática, modelagem matemática, resolução de problemas, e tecnologias da informação e comunicação.
} 
(teórico-práticos, na relação com seus outros colegas, em suas próprias experiências de formação) que lhes deem subsídios para desenvolverem práticas pedagógicas utilizando a Modelagem como orientação explícita ou, pelo menos, ações que lhe fazem referência. Com essa compreensão, estamos cientes de que a garantia de futuras práticas envolvendo Modelagem ou indícios não se esgotam nessa formação vivida pelos estagiários, isto é, a Modelagem no Estágio. Mas, segundo as compreensões emergentes, a sua inserção parece ser um caminho adequado para que experiências como estas possam romper com esse movimento de recusa à adoção de metodologias diferenciadas no âmbito das práticas de Estágio que, infelizmente, se mostra presente e de modo expressivo nas experiências vividas e descritas pelos estagiários.

Nessa linha, com as intervenções realizadas e as reflexões tecidas por esta pesquisa, esperamos que os professores, esses estagiários que vivenciaram as experiências com a Modelagem no Estágio, possam, num futuro próximo, receber e aceitar outros estagiários nas suas respectivas salas de aula, colaborando e trabalhando com Modelagem e demais Tendências Metodológicas, de modo a fortalecer sua presença na Educação Básica.

\section{Referências}

ALMEIDA, L. M. W.; SILVA, K. P.; VERTUAN, R. E. Modelagem matemática na educação básica. São Paulo: Contexto, 2013.

BARBOSA, J. C. Modelagem matemática e os professores: a questão da formação. Bolema, Rio Claro, v. 14, n. 15, p. 5-23, 2001.

BARBOSA, J. C. Sobre a pesquisa em modelagem matemática no Brasil. In: CONFERÊNCIA NACIONAL DE MODELAGEM MATEMÁTICA NA EDUCAÇÃO MATEMÁTICA, 5., 2007, Ouro Preto. Anais [...]. Ouro Preto: OFOP, 2007. v. 1, p. 82-103.

BERNSTEIN, B. Pedagogy, symbolic control and identify: theory, research, critique. Lanham: Rowman \& Littlefield, 2000.

BICUDO, M. A. V. Pesquisa qualitativa segundo a visão fenomenológica. São Paulo: Cortez, 2011.

BIEMBENGUT, M. S.; FARIA, T. M. B. Modelagem matemática na formação de professores: possibilidades e limitações. In: CONGRESSO NACIONAL DE EDUCAÇÃO, 9., 2009, Curitiba. Anais [...]. Curitiba: PUCPR, 2009. p. 10095-10109.

BRAZ, B. C. Aprendizagens sobre modelagem matemática em uma comunidade de prática de futuros professores de matemática. 2017. $253 \mathrm{f}$. Tese (Doutorado em Educação para a Ciência e a Matemática) - Centro de Ciências Exatas, Universidade Estadual de Maringá, Maringá, 2017.

CEOLIM, A. J. Modelagem matemática na educação básica: obstáculos e dificuldades apontados por professores. 2015. 151 f. Tese (Doutorado em Educação) - Centro de Educação e Ciências Humanas, Universidade Federal de São Carlos, São Carlos, 2015. 
Oliveira, W. P.; Kato, L. A.

FIORENTINI, D.; GRANDO, R. C.; MISKULIN, R. G. S.; CRECCI, V. M.; LIMA, R. C. R. de; COSTA, M. C. O professor que ensina matemática como campo de estudo: concepção do projeto de pesquisa. In: FIORENTINI, D.; PASSOS, C. L. B.; LIMA, R. C. R. (org.). Mapeamento da pesquisa acadêmica brasileira sobre o professor que ensina matemática: período 2001-2012. Campinas: Unicamp, 2016. p. 17-41.

GARNICA, A. V. M. Algumas notas sobre pesquisa qualitativa e fenomenologia.

Interface, Botucatu, v. 1, n. 1, p. 109-122, 1997. DOI: https://doi.org/10.1590/S141432831997000200008.

HERMANN, N. Hermenêutica e educação. Rio de Janeiro: DP\&A, 2002.

KLÜBER, T. E. (Des)encontros entre a modelagem matemática na educação matemática e a formação de professores de matemática. Alexandria, Florianópolis, v. 5, n. 1, p. 63-84, 2012.

MOURA, C. A. R. Crítica da razão na fenomenologia. São Paulo: Edusp: Nova Stella, 1989.

NACARATO; A. M.; PASSOS, C. L. B.; CRISTOVÃO, E. M.; MEGID, M. A. B. A.; GAMA, R. P.; COELHO, M. A. V. M. P. Tendências das pesquisas brasileiras que têm o professor que ensina matemática como campo de estudo: uma síntese dos mapeamentos regionais. In: FIORENTINI, D.; PASSOS, C. L. B.; LIMA, R. C. R. (org.). Mapeamento da pesquisa acadêmica brasileira sobre o professor que ensina matemática: período 2001-2012. Campinas: Unicamp, 2016. p. 319-350.

OLIVEIRA, A. M. P. Uma agenda de pesquisa para a modelagem matemática brasileira. In: ENCONTRO PARANAENSE DE MODELAGEM NA EDUCAÇÃO MATEMÁTICA, 7., 2016, Londrina. Anais [...] Londrina: UEL, 2016. v. 1, p. 33-43.

OLIVEIRA, W. P. Modelagem matemática nas licenciaturas em matemática das universidades estaduais do Paraná. 2016. 155 f. Dissertação (Mestrado em Educação) Universidade Estadual do Oeste do Paraná, Cascavel, 2016.

OLIVEIRA, W. P. Prática de modelagem matemática na formação inicial de professores de matemática: relato e reflexões. Revista Brasileira de Estudos Pedagógicos, Brasília, v. 98, n. 249, p. 503-521, 2017.

OLIVEIRA, W. P.; KLÜBER, T. E. Formação de professores em modelagem matemática: uma hermenêutica dos relatórios do GT 10, modelagem matemática da SBEM. Educação Matemática Pesquisa, São Paulo, v. 19, n. 2, p. 167-186, 2017.

OLIVEIRA, W. P.; KLÜBER, T. E. Metapesquisa em modelagem matemática na educação matemática: análise de artigos sobre a formação inicial de professores. Educação Online, Rio de Janeiro, n. 18, p. 144-165, 2015.

PENTEADO, M. G. Implicações para a pratica docente. In: BORBA, M. C.; PENTEADO, M. G. Informática e educação matemática. Belo Horizonte: Autêntica, 2001. p. 53-68.

PIMENTA, S. G.; LIMA, M. S. L. Estágio e docência. 2. ed. São Paulo: Cortez; 2004. 
SANT'ANA, M. F.; SANT'ANA, A. A. Modelagem matemática: relação entre formulação de perguntas e elaboração de tarefas. In: SEMINÁRIO INTERNACIONAL DE PESQUISA EM EDUCAÇÃO MATEMÁTICA, 6., 2015, Pirenópolis. Anais [...]. Pirenópolis: Sociedade Brasileira de Educação Matemática, 2015. p.1-13.

SILVA, D. K.; DALTO, J. O. Modelagem matemática na formação de professores: compartilhando uma experiência. In: ALMEIDA, L. M.W.; ARAÚJO, J. L.; BISOGNIN, E. Práticas de modelagem matemática na educação matemática: relatos de experiência e propostas pedagógicas. Londrina: Ed. da UEL, 2011. p. 181-200.

SOKOLOWSKI, R. Introdução à fenomenologia. São Paulo: Loyola, 2004.

TAMBARUSSI, C. M.; KLÜBER, T. E. Formação de professores em modelagem matemática no contexto do Programa de Desenvolvimento Educacional do Paraná, PDE. Ciência \& Educação, Bauru, v. 23, n. 4, p. 851-866, 2017. DOI: https://doi. org/10.1590/1516-731320170040007. 
